\title{
SUCCESSFUL PUBLIC HEALTH NETWORK CONFERENCE
}

$T$ he first Public Health Network Conference held at Westmead Hospital on November 23 and 24, 1992 was an outstanding success. Opening speeches were followed by five keynote presentations by invited speakers, and 38 presentations by staff of the network and related organisations.

About 80 people attended each day, and 60 went to the conference dinner. Distinguished guests from interstate and overseas were Dr Aileen Plant, of the National Centre for Population Health, and Dr John McLeod, Censor-in-Chief of the New Zealand College of Community Medicine.

The objectives of the conference were to:

\begin{tabular}{l|l} 
show the work of Public Health Officers and \\
other staff in the Public Health Network, and \\
relate this to improving health in NSW; \\
increase the profile and cohesiveness of the \\
Public Health Network; \\
facilitate linkages between staff of the network; \\
and \\
provide an efficient mechanism for discussion \\
and selection of potential 1993 assignments by \\
Public Health Officers.
\end{tabular}

Those attending the conference considered the objectives had been met.

The Director-General of the NSW Health Department, Dr Bernie Amos, opened the conference and affirmed the importance of public health to NSW. The Chief Health Officer, Dr Sue Morey, spoke on the past and future of public health in NSW and was followed by Professor Peter Baume, who spoke about public health and the political process. The Director of the New England Region Public Health Unit, Dr John Rooney, spoke on localising public health initiatives.

The keynote presentations covered Aboriginal health (Ms Liz Williams), pesticides and public health (Dr Lyn Clarke), evaluating diagnostic tests (Professor Les Irwig), screening for postnatal depression (Professor Phillip Boyce) and improving immunisation in NSW (Professor Margaret Burgess).

Other presentations were grouped as follows: Health Services and Health Economics (five presentations), Environmental Health (twelve presentations), Chronic Diseases and Injury (five), Maternal and Child Health (three) and Infectious Diseases (nine). Topics included handling data deficiency in economic evaluation ( $\mathrm{Mr}$ Richard Smith of CHERE), monitoring asthma management in the Illawarra (Dr Victoria Westley-Wise, Illawarra PHU), telephone risk factor surveys ( $\mathrm{Dr}$ Christine Roberts, Western Sector PHU), improving screening for Downs syndrome (Dr Lee Taylor, Epidemiology Branch) and the epidemiology and control of meningococcal disease in New Zealand (Dr Michael Baker, NZCDC). Abstracts from all presentations will be printed in a forthcoming issue of the Public Health Bulletin.

\begin{abstract}
A KIWI'S REFLECTIONS
consider that the NSW Public Health Network is an excellent model for public health in Australasia.

Your conference was made most enjoyable by a high general standard of presentations, the obvious talent of the participants and their emerging professionalism. The sessions highlighted our continuing need as public health professionals to strive to clearly identify the important issues, to advance public health principles in all areas of health service and to handle risk communication well. The latter is particularly crucial to re-establishing the credibility of public health in Australia and New Zealand. The presentations also highlighted clearly a number of opportunities for public health professionals to broker improved linkages among clinicians, politicians, community groups and other stakeholders.

With these comments in mind I offer the following suggestions for even greater future success. First, consider having a conference theme which addresses a current high priority issue and have several invited presentations around this theme. Follow this with submitted papers of high standard. Second, ensure that presentations facilitate clear understanding of the issues by public health decision makers and action implementers - all presentations should have a public health action message. Third, presentations and visuals should be of a high standard without the distractions of complicated graphs and unreadable tables, presenters standing in front of overheads and slowly reading information on slides. Presenters should ensure a sense of conviction about the material being presented to give that added touch of professionalism which is essential if public health practice is to be taken seriously. Fourth, important discussions should be encouraged by allowing adequate discussion time after each paper. All presenters should be required to stick to their allotted time.

I look forward to your next conference.

John W McLeod, General Manager, Planning Northern Regional Health Authority, and Censor-in-Chief, New Zealand College of Community Medicine
\end{abstract}

Professor Charles Kerr, from Sydney University, and Dr McLeod gave enjoyable speeches at the conference dinner.

At an evaluation session to consider ways of improving the conference in future years, members of the audience agreed that:

\begin{tabular}{l|l} 
- & the conference should be held annually; \\
presentations be given only by staff of the Public \\
Health Network and related organisations (e.g. \\
CHERE, NCEPH, NZCDC);
\end{tabular}




\section{Successful conference}

- Continued from page 136

- the format of presentations should be ten minutes speaking time with five minutes for questions, with the ten-minute limit strictly adhered to;

- breaks between sessions should be longer, to facilitate contact among people; the location and facilities of Westmead Hospital Education Block were well suited to the conference; more presentations should be encouraged in Aboriginal health, epidemiological methods, health promotion, mental health and chronic diseases; presentations should be more action-oriented and should conclude with a summary of the public health actions taken or recommended; staff working in the fields of HIV/AIDS, Drug and Alcohol and Mental Health, as well as local council staff and general practitioners and other clinicians, should be encouraged to attend the conference; the conference should where possible avoid parallel streams, to maintain a generalist understanding and outlook among network members; panel discussions, following a group of related presentations, should be included for important issues; and high standards of visual presentation should be encouraged.

The recommendations will be taken into account in the organisation of the next network conference.

In conclusion, the first NSW Public Health Network Conference was very successful and has provided a solid foundation for high-quality annual network conferences in the future.

\section{Mark D Bek, Public Health Officer, \\ Central and Southern Sydney Area Public Health Unit}

\section{George L Rubin, Director, \\ Epidemiology and Health Services Evaluation Branch, NSW Health Department}

\section{EDITORIAL COMMENT}

Congratulations and thanks go to Mark Bek for his outstanding efforts to make the conference the great success it was. With the able assistance of Marion Haas, Mark organised the funding, venue, program, speakers and support activities. - Editor.

\section{The NSW Health Outcomes Program}

\section{- Continued from page 135}

in the proportion of seriously injured people who receive definitive trauma care within the 'golden hour'.

In the conventional service configuration, seriously injured people are taken by ambulance to the nearest hospital which, in most instances, is a lower-level hospital and not a major trauma centre. The injured person is assessed at this hospital as having a serious injury, given initial treatment to stabilise his or her clinical condition, and then transferred to a trauma centre, arriving there after some considerable delay. Studies in western Sydney in 1988 showed that this service configuration was likely to affect outcomes adversely; only about 6 per cent of seriously injured patients reached the definitive place of care within an hour.

Consequently a reorganisation of trauma services in western Sydney was proposed, with the following elements: (i) triaging of injury cases at the place where the injury occurred by ambulance officers, using a set protocol, and (ii) immediate transport of seriously injured patients (as judged by the triage protocol) direct to major trauma centres, bypassing the local hospital. Modelling of this new approach suggested that the proportion of seriously injured patients reaching a major trauma centre within the 'golden hour' would rise from 6 per cent to 80 per cent. The modelling also showed that the shift in patient load could be managed with modest resource enhancement. The new approach was implemented in March 1992, and a preliminary evaluation has confirmed that the anticipated benefits are being realised.

This is an example of how appropriate health indicator data on a health outcome (in this instance, an intermediate outcome) have been used to identify and assess a problem, develop a plan for a new service configuration that would improve health outcomes, and then evaluate the new service when it was implemented. The plan clearly defined the roles and responsibilities of the relevant service providers such as the Ambulance Service and hospital trauma services. Further clinical indicators are being developed for continuous monitoring of the effectiveness of the service.

Michael Frommer, George Rubin and David Lyle Epidemiology and Health Services Evaluation Branch NSW Health Department

\section{PUBLIC HEALTH EDITORIAL STAFF}

The Bulletin's editorial advisory panel is as follows:

Dr Sue Morey, Chief Health Officer; Public Health Division, NSW Health Department; Professor Stephen Leeder, Director, Department of Community Medicine, Westmead Hospital; Professor Geoffrey Berry, Head, Department of Public Health, University of Sydney; Dr Christine Bennett, General Manager, Royal Hospital for Women; Dr Michael Frommer; Deputy Director, Epidemiology and Health Services Evaluation Branch, NSW Health Department; Ms Jane Hall, Director; Centre for Health Economics Research and Evaluation; and Mr Michael Ward, Manager, Health Promotion Unit. The editor is Dr George Rubin, Director, Epidemiology and Health Services Evaluation Branch, NSW Health Department.

The Bulletin aims to provide its readers with population health data and information to motivate effective public health action. Articles, news and comments should be 1,000 words or less in length and include the key points to be made in the first paragraph. Please submit items in hard copy and on diskette, preferably using WordPerfect 5.1 .

Please send to The Editor, Public Health Bulletin, Locked Mail Bag 961, North Sydney NSW 2059, Fax (02) 3919232

Design - Health Public Affairs Unit, NSW Health Department.

Suggestions for improving the content and format of the Bulletin are most welcome. Please contact your local Public Health Unit to obtain copies of the NSW Public Health Bulletin. 